\title{
Long-Term Comparison of Aesthetical Outcomes After Oncoplastic Surgery and Lumpectomy in Breast Cancer Patients
}

\author{
Gabriela Santos, MD, $\mathrm{PhD}^{\mathbf{1}}$, Cicero Urban, $\mathrm{MD}, \mathrm{PhD}^{2,7}$, Maria Isabel Edelweiss, $\mathrm{MD}, \mathrm{PhD}^{\mathbf{1}}$, \\ Gustavo Zucca-Matthes, $\mathrm{MD}, \mathrm{PhD}^{4}$, Vilmar Marques de Oliveira, $\mathrm{MD}, \mathrm{PhD}^{5}$, Gabriel Hubner Arana, $\mathrm{MD}^{6}$, \\ Marco Iera, $\mathrm{MD}^{6}$, Mario Rietjens, $\mathrm{MD}$, $\mathrm{PhD}^{6}$, Rubens Silveira de Lima, $\mathrm{MD}^{7,8}$, Cleverton Spautz, $\mathrm{MD}^{7,8}$, \\ Flávia Kuroda, $\mathrm{MD}^{7}$, Karina Anselmi, $\mathrm{MD}^{7}$, and Edison Capp, $\mathrm{MD}, \mathbf{P h D}^{1,3}$
}

${ }^{1}$ Post-Graduation Medical Program, UFRGS, Porto Alegre, Brazil; ${ }^{2}$ Positivo University, Curitiba, Brazil; ${ }^{3}$ Departament of Gynecology and Obstetrics, Hospital de Clínicas, UFRGS, Porto Alegre, Brazil; ${ }^{4}$ Breast Unit, Barretos Cancer Hospital and School of Medicine of Botucatu, UNESP/PGDGOM, Botucatu, Brazil; ${ }^{5}$ Breast Unit, Santa Casa de São Paulo, São Paulo, Brazil; ${ }^{6}$ Plastic and Reconstructive Division, European Institute of Oncology, Milan, Italy; ${ }^{7}$ Breast Unit, Hospital Nossa Senhora Graças, Curitiba, PR, Brazil; ${ }^{8}$ Tocogynecology Department, UFPR, Curitiba, Brazil

\begin{abstract}
Background. Lumpectomy may result in major deformities and asymmetries in approximately one-third of patients. Although oncoplastic surgery (OP) could be a useful alternative to avoid them, lack of strong data is causing some debate. The purpose of this study was to compare aesthetic outcomes in patients undergoing OP versus lumpectomy using three different assessment methods.
\end{abstract}

Methods. A total of 122 patients were included in this cross-sectional multicentric study; 57 underwent OP (46.7\%), and 65 underwent lumpectomy (53.3\%). Two breast surgeons and two plastic surgeons from different institutions using the Garbay scale independently evaluated aesthetic outcomes. BCCT.core software was applied in both groups, and the patients evaluated their aesthetic outcomes answering a questionnaire about their satisfaction rate.

Results. OP group had a higher proportion of excellent aesthetic results according to the BCCT.core software analysis $(p=0.028)$ and the specialists $(p=0.002)$. Multifactorial analyses showed that age $\geq 70$ years $(\mathrm{RP}=6.02$; $95 \%$ confidence interval $[\mathrm{CI}] 1.73-21.0 ; p=0.005)$, tumors in the medial, inferior, and central quadrants $(\mathrm{RP}=4.21 ; 95 \% \mathrm{CI}$ $1.88-9.44 ; p<0.001)$, and large breasts $(\mathrm{RP}=7.55 ; 95 \% \mathrm{CI}$

(C) Society of Surgical Oncology 2014

First Received: 17 August 2014;

Published Online: 18 December 2014

C. Urban, $\mathrm{MD}, \mathrm{PhD}$

e-mail: cicerourban@hotmail.com
2.48-23.0; $p<0.001)$ were significant risk factors for poor aesthetic outcomes after lumpectomy. The patients classified their results as better than those by the specialists and by the software, with no statistical difference between the groups.

Conclusions. Excellent aesthetic results were more frequent in the OP group according to BCCT.core software analysis and specialists. In addition, some clinical conditions and tumor locations in the breast can be considered risky factors for poor aesthetic outcomes in lumpectomy.

It is expected that nearly one-third of lumpectomies will result in major deformities and asymmetries, potentially having a negative impact on the quality of life of patients. ${ }^{1-3}$ Thus, from the 1980 s on, and especially in the 1990s, the oncoplastic surgery (OP) concept has been developed, combining both aesthetic and cancer surgery techniques. The purpose was to reduce the risk of late deformities and asymmetry after lumpectomy. In addition, these new techniques have broadened the indications for breast-conserving treatment (BCT), especially in patients with larger tumors, with the benefit of avoiding mastectomy in some cases. In addition, its philosophy is that the appearance of the breast and the quality of life of the patients should be components of the breast cancer treatment.

For women facing BCT, good aesthetic outcome is one of the main goals, and therefore measurement of this is critical for a better selection of the patients in clinical practice. Although OP has been receiving widespread attention as a good approach to avoid deformities in BCT, lack of strong 
data has led to some debate about its real impact. Many individualized tools have been developed for its aesthetic evaluation. Parameters related to symmetry, differences in color, and resulting scars were analyzed in different scales. Some of them have been designed for the evaluation of the aesthetic outcomes by the surgeons, and others are patientreported outcomes. ${ }^{1,4-7}$ Current methods vary widely and could be complementary, because their focus are patient and surgeon-centered assessment methods. In addition, the software breast cancer conservative treatment cosmetic results (BCCT.core) is an objective and valid method developed for the evaluation of aesthetic outcomes in BCT. ${ }^{4}$ However, it was not applied until now in OP.

Consequently, comparative data between aesthetic outcomes in lumpectomy and OP are limited to a few series in the literature. Therefore, the purpose of this study was to evaluate the aesthetic outcomes in patients with breast cancer undergoing lumpectomy and OP using the software breast cancer conservative treatment cosmetic results (BCCT.core), patient's, and surgeon's aesthetic evaluations. ${ }^{4}$

\section{PATIENTS AND METHODS}

This is a cross-sectional, multicentric, two-independentgroup study, with patients undergoing BCT, in which the first group underwent level 2 OP techniques (bilateral surgeries with mammaplasty techniques) at the Hospital Nossa Senhora das Graças (HNSG) Breast Unit in Curitiba (Brazil). The second group underwent lumpectomy with incisions over the tumor, without removing skin (except in cases where the tumors where close to skin). Breast parenchymal reapproximation was performed in all cases, followed by intradermal suture, at three different hospitals in Novo Hamburgo: Unimed, Regina, and Municipal, between 2007 and 2012, by the same breast surgeon (GS).

All patients were included in this study who were diagnosed with ductal carcinoma in situ or invasive carcinomas (T1-T2), diagnosed by core-biopsy or mammotome, who were candidates for BCT through evaluation by clinical exam, mammography, ultrasonography, and/or magnetic resonance imaging. All participants agreed to take part in the study and have signed an informed consent form. In order to be included in this study, all patients had to be finished their treatments, and be at least 6 months after the conclusion of radiotherapy.

All patients were photographed with a Nikon 10.0 megapixels camera in the frontal, semi-profile, and bilateral profile views, in front of a dark background, and from the same distance $(2 \mathrm{~m})$ between them and the photographer (Figs. 1, 2). The objective aesthetic analysis was performed by two independent plastic surgeons from the European Institute of Oncology in Milan (Italy), and two breast surgeons-one from Hospital de Cancer de Barretos
(Brazil), and other one from Hospital Santa Casa de São Paulo (Brazil). They independently evaluated the volume, shape, breast symmetry, position of the inframammary fold, and the scars, according to Garbay's criteria. ${ }^{5}$ The conclusions were graded from 0 to 10 . Zero corresponded to worst and 10 to the best result. The patients also answered a questionnaire about their satisfaction rate with the aesthetic results, and their answers were graded as excellent, good, regular, and unsatisfactory.

The aesthetic results were also evaluated with the use of BCCT.core software. The BCCT.core software summarizes all objective symmetry measurements. This software carries out a semiautomatic analysis of torso photographs in an anterior-posterior view. The examiner designates (predetermined points), followed by automated software calculations of different relational symmetry measurements including: breast volume, skin color and scars. An algorithm combines all the measurement results into an overall aesthetic score. The final results are based on a four-point scale: excellent, good, fair, and poor. ${ }^{4,8,9}$ This study was approved by the Internal Review Board from Positivo University, in Curitiba, Brazil.

\section{Statistical Analyses}

The quantitative variables were described through average and standard deviation (symmetric distribution) or median and interquartile range (asymmetric distribution). The categorical variables were described by absolute and relative frequencies. To compare averages between the groups, the $t$ test was applied. In cases of asymmetry, the Mann-Whitney was used. For the comparison of proportions, the Pearson test or Fisher exact-test was applied. To complement these analyses, the adjusted residuals test was used. For the concordance among specialists, software and patients, kappa coefficient was applied. The concordance power is established by the following manner: $<0.2=$ poor; between 0.21 and $0.40=$ fair; between 0.41 and $0.60=$ moderate; between 0.61 and $0.80=$ good and $>0.80=$ very good. To control confounding factors, Poisson regression analysis (outcome variable: aesthetic results) or analysis of covariance (outcome variable: SF-36 scores) were used. The criterion for the inclusion of the variable in the multivariate model was that it presented a $p$ value $<0.20$ in the bivariate analysis. The level of significance adopted was $5 \%(p \leq 0.05)$, and the analyses were performed in the SPSS program version 18.0.

\section{RESULTS}

A total of 122 patients were included in this study. Among them, 57 underwent OP $(46.7 \%)$, and 65 

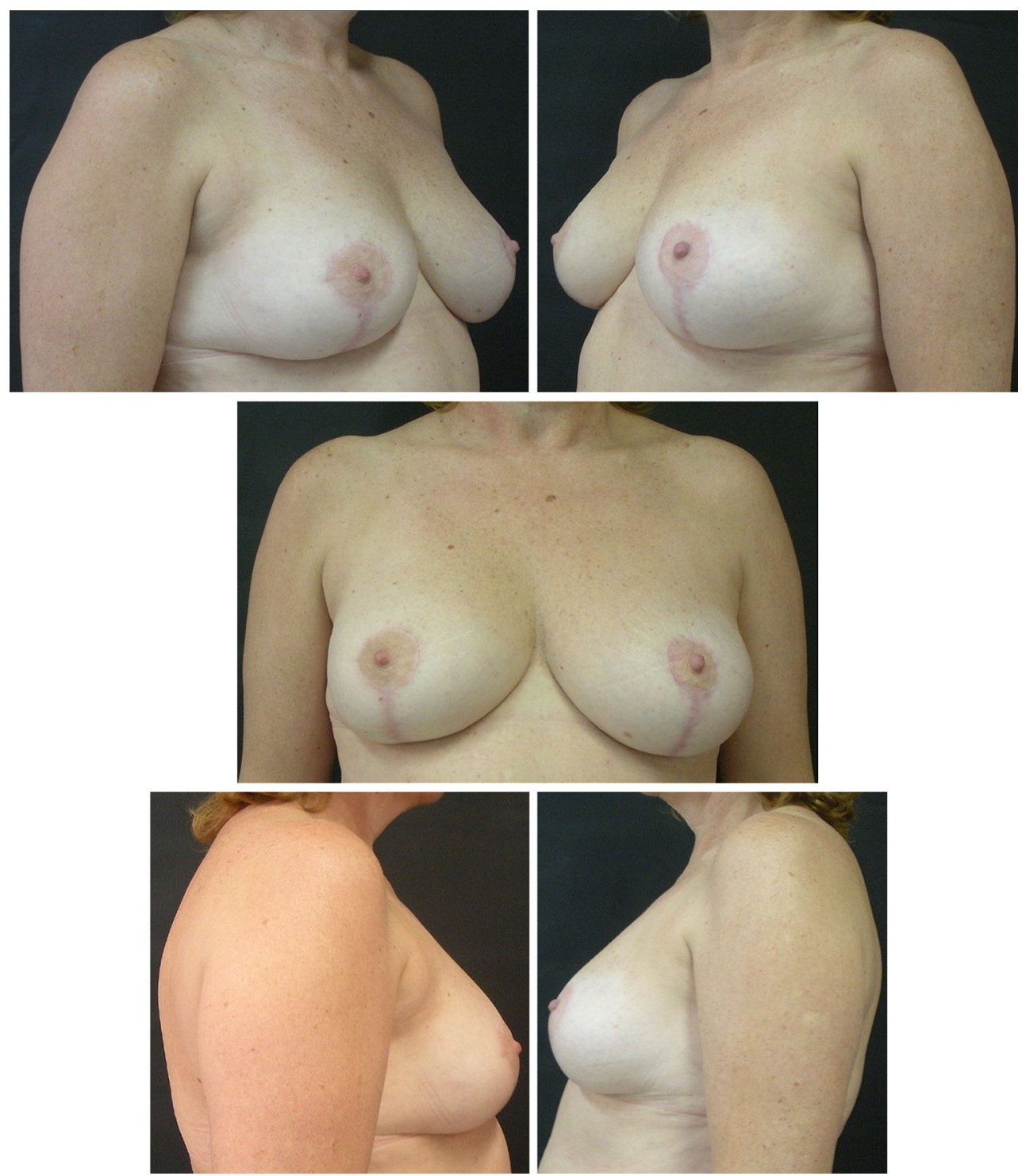

FIG. 1 Method of oncoplastic surgery photos for specialist's analysis

underwent lumpectomy $(53.3 \%)$. The demographic and oncologic characteristics of the two groups are presented in Table 1. In the OP group, 38 patients $(66.7 \%)$ underwent inferior pedicle techniques, 17 (29.9\%) superior pedicle, 1 central quadrantectomy (1.7\%; contralateral symmetry in this case was with inferior pedicle), and $1(1.7 \%)$ round block. Both groups were similar in most of variables, but time between the surgery and the study analysis was shorter in OP group $(p=0.047)$. The educational level in OP group was higher $(p<0.001)$, as was their average body mass index $(\mathrm{BMI})(p=0.012)$. In addition, in the $\mathrm{OP}$ group all were patients in the private system, while the lumpectomy group had $38 \%$ of patients from the Brazilian public health system (SUS).

Invasive ductal carcinoma was the most frequent diagnosis, corresponding to $67.3 \%$ in OP group and to $86.2 \%$ in lumpectomy group. Both groups showed a high prevalence of associated ductal carcinoma in situ, with $66 \%$ in the OP group and $79.7 \%$ in lumpectomy group. The weight of the surgical specimen was higher in the OP group, ranging from 40 to $121 \mathrm{~g}$. The sentinel node biopsy was performed in 49 patients of the OP group $(94.2 \%)$ and 59 patients in lumpectomy group $(92.2 \%)$. There were more patients with axillary metastases in lumpectomy group. The reoperative rates were similar in both groups.

The OP patients showed a considerably higher proportion of excellent aesthetic outcomes, classified both by software $(p=0.028)$ and by specialists $(p=0.002$; Table 2). The association of the aesthetic results with the tumor location, size of the breasts, and tumor size with the type of surgery is presented in Table 3. This association was relevant only in lumpectomy patients. Patients with 

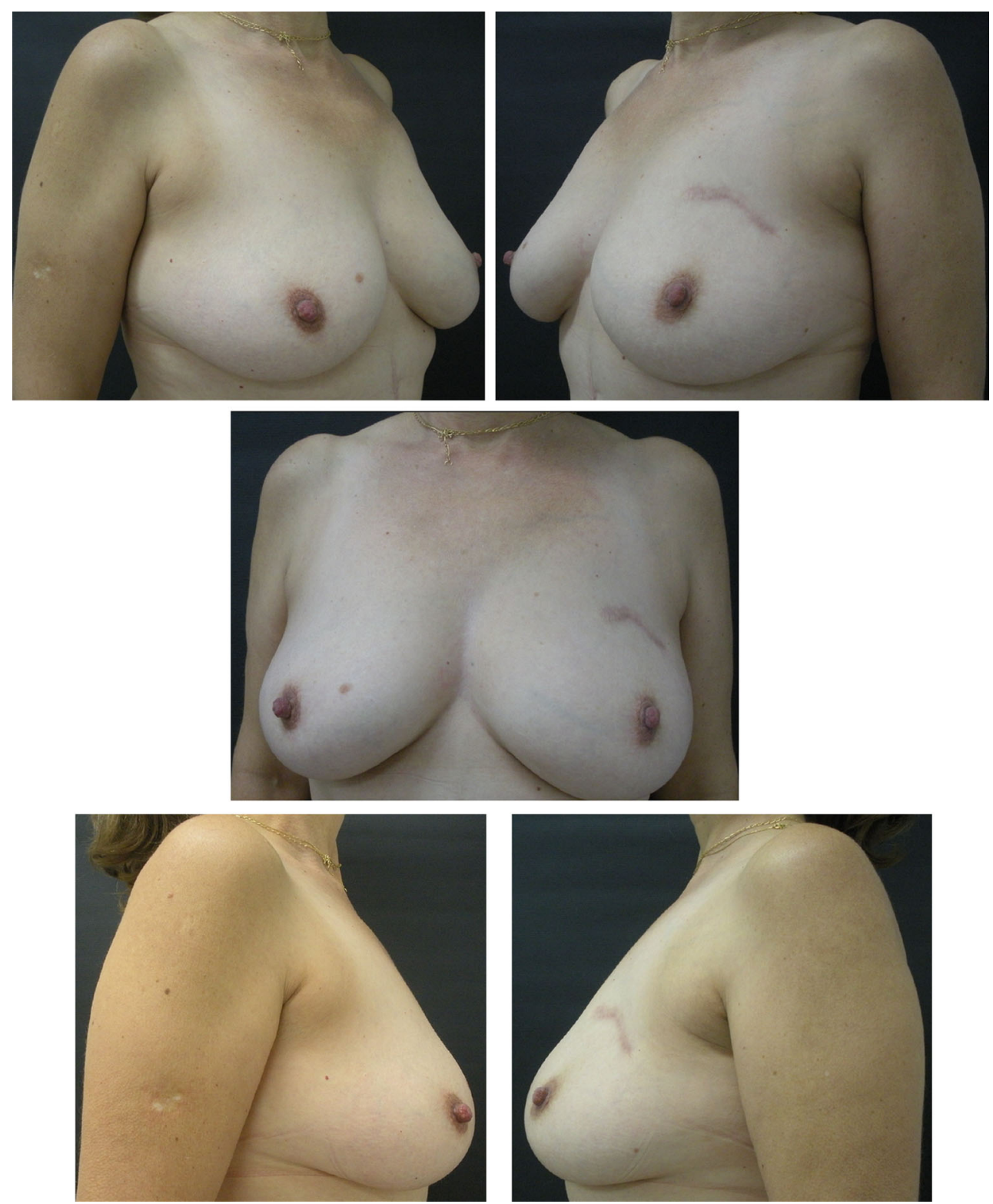

FIG. 2 Method of lumpectomy photos for specialist's analysis

large breasts had worse aesthetic results in lumpectomy group. Multifactorial analyses with Poisson's regression showed that age $\geq 70$ years $(\mathrm{RP}=6.02 ; 95 \%$ confidence interval $[\mathrm{CI}] 1.73-21.0 ; p=0.005)$, tumors in the medial, inferior and central quadrants $(\mathrm{RP}=4.21 ; 95 \% \mathrm{CI} 1.88$ 9.44; $p<0,001)$, and large breasts ( $\mathrm{RP}=7.55 ; 95 \% \mathrm{CI}$ $2.48-23.0 ; p<0.001)$ were significant risk factors for poor aesthetic outcome after lumpectomy.

Concordance among the four specialists was significant (kappa $=0.20 ; p<0.001)$ but was considered poor, according to the Altman criteria (1991). When the concordance in each category was evaluated, it was observed that the categories "excellent" (kappa $=0.32)$ and "bad" $(\mathrm{kappa}=0.29)$ showed a higher degree of concordance than the categories "good" (kappa $=0.10)$ and "regular" $(\mathrm{kappa}=0.11)$. When the concordance between the four specialists and the BCCT.core was evaluated, it was found a poor concordance (kappa $=0.12 ; p=0.047$ ). There were relevant differences between the aesthetic evaluation by the specialists, the patients and the software $(p<0.001)$. The patients classified their results as better than the software.

\section{DISCUSSION}

Aesthetic results after lumpectomy may be unsatisfactory in approximately $30 \%$ of the patients. ${ }^{10,11}$ Both the deformity and asymmetry between the breasts remain as a 
TABLE 1 Patient and tumor characteristics in oncoplastic surgery and lumpectomy

\begin{tabular}{|c|c|c|c|}
\hline & Oncoplastic group $(n=57)$ & Lumpectomy group $(n=65)$ & $p$ \\
\hline Patient age (years) & $58.4 \pm 11.3$ & $54.7 \pm 10.6$ & 0.061 \\
\hline Menopausal status & & & 0.623 \\
\hline Pre & $16(28.1)$ & $22(33.8)$ & \\
\hline Post & $41(71.9)$ & $43(66.2)$ & \\
\hline Follow-up time (months) & $36.2 \pm 19.8$ & $40.8 \pm 16.3$ & 0.170 \\
\hline Time gap between the surgery and the photo (months) & $26.6 \pm 14.8$ & $32.0 \pm 14.8$ & 0.047 \\
\hline $\mathrm{pT}-n(\%)$ & & & 0.074 \\
\hline pTis & $7(13.2)$ & $2(3.1)$ & \\
\hline pT1a/pT1b/pT1c & $36(67.9)$ & $44(67.7)$ & \\
\hline pT2 & $10(18.9)$ & $19(29.2)$ & \\
\hline Education level一 $-n(\%)$ & & & $<0.001$ \\
\hline Unfinished primary school & $4(7.0)$ & $21(32.3)$ & \\
\hline Full primary school & $11(19.3)$ & $13(20.0)$ & \\
\hline High school & $9(15.8)$ & $18(27.7)^{\mathrm{a}}$ & \\
\hline College degree & $20(35.1)^{\mathrm{a}}$ & $8(12.3)$ & \\
\hline Specialization, Post-degree, Master's degree, Doctor's degree & $13(22.8)^{\mathrm{a}}$ & $5(7.7)$ & \\
\hline $\mathrm{BMI}-n(\%)$ & & & 0.012 \\
\hline Underweight & $0(0.0)$ & $1(1.5)$ & \\
\hline Normal (healthy weight) & $23(40.4)$ & $32(49.2)$ & \\
\hline Overweight & $27(47.4)^{\mathrm{a}}$ & $14(21.5)$ & \\
\hline Obese class & $7(12.3)$ & $18(27.7)^{\mathrm{a}}$ & \\
\hline Breast size $-n(\%)$ & & & 0.162 \\
\hline Small & $1(1.8)$ & $3(4.6)$ & \\
\hline Medium & $22(38.6)$ & $34(52.3)$ & \\
\hline Large/extra large & $34(59.6)$ & $28(43.1)$ & \\
\hline Histological type- $n(\%)$ & & & 0.022 \\
\hline Ductal carcinoma invasive & $37(67.3)$ & $56(86.2)^{\mathrm{a}}$ & \\
\hline Ductal carcinoma in situ & $8(14.5)^{\mathrm{a}}$ & $2(3.1)$ & \\
\hline Lobular carcinoma in situ & $4(7.3)$ & $6(9.2)$ & \\
\hline Mucinous carcinoma & $4(7.3)^{\mathrm{a}}$ & $0(0.0)$ & \\
\hline Others & $2(3.6)$ & $1(1.5)$ & \\
\hline CDIS & & & 0.152 \\
\hline No & $17(34.0)$ & $13(20.3)$ & \\
\hline Yes & $33(66.0)$ & $51(79.3)$ & \\
\hline Tumor localization- $-n(\%)$ & & & 0.316 \\
\hline Upper outer quadrant & $14(26.4)$ & $22(33.8)$ & \\
\hline Lower outer quadrant & $10(18.9)$ & $4(6.2)$ & \\
\hline Lower inner quadrant & $2(3.8)$ & $5(7.7)$ & \\
\hline Upper inner quadrant & $4(7.5)$ & $8(12.3)$ & \\
\hline Superior quadrants intersection & $8(15.1)$ & $10(15.4)$ & \\
\hline Internal quadrants intersection & $3(5.7)$ & $1(1.5)$ & \\
\hline Inferior quadrants intersection & $4(7.5)$ & $9(13.8)$ & \\
\hline External quadrants intersection & $7(13.2)$ & $5(7.7)$ & \\
\hline Central quadrant & $1(1.9)$ & $1(1.5)$ & \\
\hline Weight $(\mathrm{g})-$ median $(\mathrm{P} 25-\mathrm{P} 75)$ & $59(40-121)$ & $45.5(19-57)$ & 0.017 \\
\hline Tumor size $(\mathrm{cm})$ & $1.50 \pm 0.96$ & $1.63 \pm 0.84$ & 0.447 \\
\hline $\mathrm{pN}-n(\%)$ & & & 0.031 \\
\hline 0 & $42(85.7)^{\mathrm{a}}$ & $44(68.8)$ & \\
\hline
\end{tabular}


TABLE 1 continued

\begin{tabular}{|c|c|c|c|}
\hline & Oncoplastic group $(n=57)$ & Lumpectomy group $(n=65)$ & $p$ \\
\hline 1 & $7(14.3)$ & $13(20.3)$ & \\
\hline 2 & $0(0.0)$ & $7(10.9)^{\mathrm{a}}$ & \\
\hline Grade $-n(\%)$ & & & 0.412 \\
\hline 1 & $11(20.8)$ & $18(28.6)$ & \\
\hline 2 & $26(49.1)$ & $32(50.8)$ & \\
\hline 3 & $16(30.2)$ & $13(20.6)$ & \\
\hline Sentinel node biopsy- $n(\%)$ & & & 0.729 \\
\hline No & $3(5.8)$ & $5(7.8)$ & \\
\hline Yes & $49(94.2)$ & $59(92.2)$ & \\
\hline Estrogen receptor- $n(\%)$ & & & 0.617 \\
\hline Negative & $11(22.4)$ & $11(16.9)$ & \\
\hline Positive & $38(77.6)$ & $54(83.1)$ & \\
\hline Progesterone receptor- $n(\%)$ & & & 0.653 \\
\hline Negative & $14(28.6)$ & $15(23.1)$ & \\
\hline Positive & $35(71.4)$ & $50(76.9)$ & \\
\hline HER2-n $(\%)$ & & & 0.560 \\
\hline Negative & $33(70.2)$ & $51(78.5)$ & \\
\hline Positive & $9(19.1)$ & $10(15.4)$ & \\
\hline Uncertain & $5(10.6)$ & $4(6.2)$ & \\
\hline
\end{tabular}

${ }^{a}$ Statistically significant association by testing waste set at $5 \%$ significance

TABLE 2 Comparison of aesthetic results between the oncoplastic surgery and lumpectomy

\begin{tabular}{|c|c|c|c|c|}
\hline & Oncoplastic group $(n=57)$ & Lumpectomy group $(n=65)$ & $p$ & $p$ adjusted $*$ \\
\hline BCCT.core- $n(\%)$ & & & 0.028 & 0.004 \\
\hline Excellent & $13(22.8)^{\mathrm{a}}$ & $4(6.2)$ & & \\
\hline Good & $31(54.4)$ & $48(73.8)^{\mathrm{a}}$ & & \\
\hline Regular & $12(21.1)$ & $10(15.4)$ & & \\
\hline $\mathrm{Bad}$ & $1(1.8)$ & $3(4.6)$ & & \\
\hline Specialists- $n(\%)$ & & & 0.002 & $<0.001$ \\
\hline Excellent & $29(50.9)^{\mathrm{a}}$ & $12(18.5)$ & & \\
\hline Good & $23(40.4)$ & $40(61.5)^{\mathrm{a}}$ & & \\
\hline Regular & $4(7.0)$ & $12(18.5)$ & & \\
\hline Bad & $1(1.8)$ & $1(1.5)$ & & \\
\hline Patients- $n(\%)$ & & & 0.242 & 0.320 \\
\hline Excellent & 35 (61.4) & $45(69.2)$ & & \\
\hline Good & $17(29.8)$ & $19(29.2)$ & & \\
\hline Regular & $2(3.5)$ & $1(1.5)$ & & \\
\hline $\mathrm{Bad}$ & $3(5.3)$ & $0(0.0)$ & & \\
\hline
\end{tabular}

* Multivariate analysis adjusted by age, follow-up time, time gap between the surgery and the photo, pT, education level, BMI, breast size, histological type, DCIS, and pN

${ }^{\text {a }}$ Statistically significant association by adjusted residual at $5 \%$ significance

reminder of the disease and, therefore, interferes in the psychological adaptation and return to normality. The rate of unsatisfactory results in OP ranges from 0 to $18 \%$ in the literature. ${ }^{12-27}$ Therefore, an adequate selection of patients can reduce this by $25-30 \%{ }^{13}$
Many other factors can influence aesthetic results after lumpectomy: age, BMI, size and location of the tumor, breast size, as well as the adjuvant treatment applied. Our findings showed an association of increased age with unsatisfactory results in the lumpectomy group, especially 
TABLE 3 Association of the aesthetic results with different variables in oncoplastic surgery and lumpectomy

\begin{tabular}{|c|c|c|c|c|c|c|}
\hline \multirow[b]{2}{*}{ Variable $^{\mathrm{a}}$} & \multicolumn{3}{|c|}{ Oncoplastic group } & \multicolumn{3}{|c|}{ Lumpectomy group } \\
\hline & Excellent/good & Regular/bad & $p$ & Excellent/good & Regular/bad & $p$ \\
\hline Age (years) & $59.3 \pm 10.8$ & $55.6 \pm 13.1$ & 0.316 & $53.4 \pm 10.2$ & $59.6 \pm 11.1$ & 0.061 \\
\hline$<70$ & $38(88.4)$ & $11(84.6)$ & & $50(96.2)$ & $10(76.9)$ & \\
\hline$\geq 70$ & $5(11.6)$ & $2(15.4)$ & & $2(3.8)$ & $3(23.1)$ & \\
\hline Obesity & $4(9.1)$ & $3(23.1)$ & 0.333 & $13(25.0)$ & $6(46.2)$ & 0.176 \\
\hline Tumor localization $n(\%)$ & & & 0.466 & & & 0.068 \\
\hline Upper outer quadrant & $11(26.2)$ & $3(27.3)$ & & $20(38.5)$ & $2(15.4)$ & \\
\hline Lower outer quadrant & $6(14.3)$ & $4(36.4)$ & & $3(5.8)$ & $1(7.7)$ & \\
\hline Lower inner quadrant & $1(2.4)$ & $1(9.1)$ & & $4(7.7)$ & $1(7.7)$ & \\
\hline Upper inner quadrant & $4(9.5)$ & $0(0.0)$ & & $7(13.5)$ & $1(7.7)$ & \\
\hline Superior quadrants intersection & $6(14.3)$ & $2(18.2)$ & & $8(15.4)$ & $2(15.4)$ & \\
\hline Internal quadrants intersection & $3(7.1)$ & $0(0.0)$ & & $0(0.0)$ & $1(7.7)$ & \\
\hline Inferior quadrants intersection & $4(9.5)$ & $0(0.0)$ & & $5(9.6)$ & $4(30.8)$ & \\
\hline External quadrants intersection & $6(14.3)$ & $1(9.1)$ & & $5(9.6)$ & $0(0.0)$ & \\
\hline Central quadrant & $1(2.4)$ & $0(0.0)$ & & $0(0.0)$ & $1(7.7)$ & \\
\hline pT $n(\%)$ & & & 0.528 & & & 0.357 \\
\hline pTis & $6(14.3)$ & $1(9.1)$ & & $1(1.9)$ & $1(7.7)$ & \\
\hline $\mathrm{pT} 1 \mathrm{a} / \mathrm{pT} 1 \mathrm{~b} / \mathrm{pT} 1 \mathrm{c}$ & $27(64.3)$ & $9(81.8)$ & & $37(71.2)$ & $7(53.8)$ & \\
\hline pT2 & $9(21.4)$ & $1(9.1)$ & & $14(26.9)$ & $5(38.5)$ & \\
\hline Breast size $-n(\%)$ & & & 0.402 & & & 0.003 \\
\hline Small & $1(2.3)$ & $0(0.0)$ & & $3(5.8)$ & $0(0.0)$ & \\
\hline Medium & $15(34.1)$ & $7(53.8)$ & & $32(61.5)^{\mathrm{b}}$ & $2(15.4)$ & \\
\hline Large/extra large & $28(63.6)$ & $6(46.2)$ & & $17(32.7)$ & $11(84.6)^{\mathrm{b}}$ & \\
\hline
\end{tabular}

${ }^{\text {a }}$ Expressed as mean \pm standard deviation or $n(\%)$

b Statistically significant association by testing waste set at $5 \%$ significance

in patients older than age 70 years. ${ }^{28}$ Approximately $35 \%$ of breast tumors are located in the lower (inner or outer) quadrants, ${ }^{29}$ and in lumpectomy this localization is a risk one (the same for inner and central quadrants), because loss of tissue there can distort and lower the nipple and areola complex. Another relevant data in our series was in relation to the breast size, because larger breasts were related with worse aesthetic outcomes in the lumpectomy group. In these larger-breasted women, OP has an important role for the improvement of aesthetic results and patients' satisfaction. In addition, OP results in lower risk of compromised margins in these patients. Significantly reducing breast size also improves and simplifies radiotherapy planning. ${ }^{28}$

The rates of satisfactory aesthetic results are encouraging with $\mathrm{OP}$, as they range between 84 and $89 \%$ compared with lumpectomy, which range from 60 to $80 \%{ }^{30} \mathrm{~A}$ recent meta-analysis showed significantly higher satisfaction with aesthetic results, in the OP group (89.5 vs. $82.9 \%$ in lumpectomy; $p<0.001) .{ }^{31}$ Our results showed that the evaluation by the specialists is similar to the ones mentioned in previous studies, with $91.3 \%$ in the OP group and $80 \%$ in lumpectomy.
Patients' self-evaluation is, certainly, the easiest one to perform. However, reproducibility is low, because it usually reflects their expectations before the surgery and psychosocial adaptation with the aesthetic results. Several factors, such as age and differences in social and economic levels, could influence the satisfaction rate and final analysis by the patients. Usually, patients considered their results more favorable than specialists. ${ }^{8,32-34}$ Thus, our data are in agreement with the literature, as the patients classified their results as better than those by the specialists and by the software. In addition, there were differences in educational level (lower in the lumpectomy group), and the proportion of public health care patients (higher in lumpectomy group). In Brazil, it is frequently observed in daily practice that the expectations are higher in private practice and in patients with higher formal education. These factors can interfere with the patient's self-evaluation results in our series.

The most common subjective method used in practice is the evaluation by specialists. ${ }^{1,35}$ Many authors have employed a variant of the scale originally described by Harris, which divides outcomes into four categories: excellent, good, fair, or poor. ${ }^{4,33,36}$ In 2011, Veiga evaluated 45 breast cancer patients undergoing OP and 45 
patients treated by lumpectomy, applying the subscales modified Garbay scale. ${ }^{1}$ This scale takes more in account on some specific details in relation to symmetry, which, could be better for evaluation in OP. Although this could be a more meticulous method, its interobserver agreement was low here. In our study we used this scale, and observed a poor agreement between all surgeons and between plastic surgeons and breast surgeons too.

The BCCT.core software, is an objective method developed for the evaluation of aesthetic results in lumpectomy through photographic records of the patients in the anteroposterior position, analyzing parameters related to symmetry, differences in color and scarring, and through the points of reference compiled by the user (contour of breasts, nipples, and sternal furcula). ${ }^{4}$ Results are classified as excellent, good, fair and poor. Some studies have shown their utility, observing concordance with the results obtained through the software in comparison with the evaluations by the observers using the Harris scale., ${ }^{4,35}$ In our series, this software was applied for the first time in OP. Concordance between the specialists and the software was considered poor $(K=0.12)$. We believe that this, in part, was due to the use of the Garbay scale instead of Harris scale. Although Harris' scale is a good methodology for aesthetic evaluation in breast conserving surgery, Garbay's scale, in our view, takes more account on some specific details in relation to symmetry, which could be better for evaluation in OP. Another important point that could explain this result is that the software evaluation analyse the breasts in a single position, whereas specialists analyzed in three positions, as shown in Figs. 1 and 2.

The subjective and objective methods are complementary, and it is important to consider patient's opinion too. Objective methods might be more useful for the choice surgical technique itself, evaluating the symmetry between the breasts. In our study, OP patients had a significantly higher proportion of excellent aesthetic results evaluated through both software $(p=0.024)$ and by specialists $(p=0.002)$. Modest asymmetry registered by the software may not be relevant for the patients, and their evaluation, many times, can be affected by sociocultural elements. It is important to consider, however, that better results confirmed by the software, as in OP cases, mean more symmetric breasts and consequently could be positive for more satisfaction of the patients.

\section{CONCLUSIONS}

The original focus of OP was to maintain and even to improve quality of life of patients, because most of them are expected to enjoy long-term survival. ${ }^{32}$ Results considered excellent both in subjective and objective evaluation were more frequent in patients undergoing OP. In addition, there are locations in the breast that can be considered as risky for poor aesthetic results in lumpectomy. Large breasts and advanced age also were determined factors associated with unsatisfactory results in lumpectomy. In these selected cases, OP should be considered a better option than lumpectomy.

\section{REFERENCES}

1. Veiga DF, Veiga-Filho J, Ribeiro LM, Archangelo-Junior I, Mendes DA, Andrade VO, et al. Evaluations of aesthetic outcomes of oncoplastic surgery by surgeons of different gender and specialty: a prospective controlled study. Breast. 2011;20(5):407-12.

2. Veronesi U, Cascinelli N, Mariani L, Greco M, Saccozzi R, Luini A, et al. Twenty-year follow-up of a randomized study comparing breast-conserving surgery with radical mastectomy for early breast cancer. $N$ Engl J Med. 2002;347(16):1227-32.

3. Fisher B, Anderson S, Bryant J, Margolese RG, Deutsch M, Fisher ER, et al. Twenty-year follow-up of a randomized trial comparing total mastectomy, lumpectomy, and lumpectomy plus irradiation for the treatment of invasive breast cancer. $N$ Engl J Med. 2002;347(16):1233-41.

4. Cardoso MJ, Cardoso J, Amaral N, Azevedo I, Barreau L, Bernardo M, et al. Turning subjective into objective: the BCCT.core software for evaluation of cosmetic results in breast cancer conservative treatment. Breast. 2007;16(5):456-61.

5. Garbay JR, Rietjens M, Petit JY. Esthetic results of breast reconstruction after amputation for cancer. 323 cases. J Gynecol Obstet Biol Reprod (Paris). 1992;21(4):405-12.

6. Veiga DF, Neto MS, Garcia EB, Filho JV, Juliano Y, Ferreira LM, et al. Evaluations of the aesthetic results and patient satisfaction with the late pedicled TRAM flap breast reconstruction. Ann Plast Surg. 2002;48(5):515-20.

7. Lowery JC, Wilkins EG, Kuzon WM, Davis JA. Evaluations of aesthetic results in breast reconstruction: an analysis of reliability. Ann Plast Surg. 1996;36(6):601-6; discussion 7.

8. Heil J, Dahlkamp J, Golatta M, Rom J, Domschke C, Rauch G, et al. Aesthetics in breast conserving therapy: do objectively measured results match patients' evaluations? Ann Surg Oncol. 2011;18(1):134-8.

9. Cardoso MJ, Cardoso J, Santos AC, Barros H, Cardoso de Oliveira $\mathrm{M}$. Interobserver agreement and consensus over the esthetic evaluation of conservative treatment for breast cancer. Breast. 2006;15(1):52-7.

10. Curran D, van Dongen JP, Aaronson NK, Kiebert G, Fentiman IS, Mignolet F, et al. Quality of life of early-stage breast cancer patients treated with radical mastectomy or breast-conserving procedures: results of EORTC Trial 10801. The European Organization for Research and Treatment of Cancer (EORTC), Breast Cancer Co-operative Group (BCCG). Eur J Cancer. 1998;34(3):307-14.

11. Kronowitz SJ, Feledy JA, Hunt KK, Kuerer HM, Youssef A, Koutz CA, et al. Determining the optimal approach to breast reconstruction after partial mastectomy. Plast Reconstr Surg. 2006;117(1):1-11; discussion 2-4.

12. Asgeirsson KS, Rasheed T, McCulley SJ, Macmillan RD. Oncological and cosmetic outcomes of oncoplastic breast conserving surgery. Eur J Surg Oncol. 2005;31(8):817-23.

13. Berry MG, Fitoussi AD, Curnier A, Couturaud B, Salmon RJ. Oncoplastic breast surgery: a review and systematic approach. $J$ Plast Reconstr Aesth Surg. 2010;63(8):1233-43. 
14. Chang E, Johnson N, Webber B, Booth J, Rahhal D, Gannett D, et al. Bilateral reduction mammoplasty in combination with lumpectomy for treatment of breast cancer in patients with macromastia. Am J Surg. 2004;187(5):647-50; discussion 50-1.

15. Clough KB, Lewis JS, Couturaud B, Fitoussi A, Nos C, Falcou MC. Oncoplastic techniques allow extensive resections for breast-conserving therapy of breast carcinomas. Ann Surg. 2003;237(1):26-34.

16. Dixon JM, Venizelos B, Chan P. Latissimus dorsi mini-flap: a technique for extending breast conservation. Breast. 2002;11(1):58-65.

17. Galimberti V, Zurrida S, Zanini V, Callegari M, Veronesi P, Catania S, et al. Central small size breast cancer: how to overcome the problem of nipple and areola involvement. Eur $J$ Cancer. 1993;29A(8):1093-6.

18. Gendy RK, Able JA, Rainsbury RM. Impact of skin-sparing mastectomy with immediate reconstruction and breast-sparing reconstruction with miniflaps on the outcomes of oncoplastic breast surgery. Br J Surg. 2003;90(4):433-9.

19. Kat CC, Darcy CM, O’Donoghue JM, Taylor AR, Regan PJ. The use of the latissimus dorsi musculocutaneous flap for immediate correction of the deformity resulting from breast conservation surgery. Br J Plast Surg. 1999;52(2):99-103.

20. Masetti R, Pirulli PG, Magno S, Franceschini G, Chiesa F, Antinori A. Oncoplastic techniques in the conservative surgical treatment of breast cancer. Breast Cancer. 2000;7(4):276-80.

21. Nano MT, Gill PG, Kollias J, Bochner MA. Breast volume replacement using the latissimus dorsi miniflap. ANZ J Surg. 2004;74(3):98-104.

22. Newman LA, Kuerer HM, McNeese MD, Hunt KK, Gurtner GC, Vlastos GS, et al. Reduction mammoplasty improves breast conservation therapy in patients with macromastia. Am J Surg. 2001;181(3):215-20.

23. Noguchi M, Taniya T, Miyazaki I, Saito Y. Immediate transposition of a latissimus dorsi muscle for correcting a postquadrantectomy breast deformity in Japanese patients. Int Surg. 1990;75(3):166-70.

24. Nos C, Fitoussi A, Bourgeois D, Fourquet A, Salmon RJ, Clough KB. Conservative treatment of lower pole breast cancers by bilateral mammoplasty and radiotherapy. Eur J Surg Oncol. 1998;24(6):508-14.

25. Papp C, Wechselberger G, Schoeller T. Autologous breast reconstruction after breast-conserving cancer surgery. Plast Reconstr Surg. 1998;102(6):1932-6; discussion 7-8.
26. Petit J, Rietjens M, Garusi C. Breast reconstructive techniques in cancer patients: which ones, when to apply, which immediate and long term risks? Crit Rev Oncol Hematol. 2001;38(3):231-9.

27. Spear SL, Pelletiere CV, Wolfe AJ, Tsangaris TN, Pennanen MF. Experience with reduction mammaplasty combined with breast conservation therapy in the treatment of breast cancer. Plast Reconstr Surg. 2003;111(3):1102-9.

28. Urban C, Lima R, Schunemann E, Spautz C, Rabinovich I, Anselmi K. Oncoplastic principles in breast conserving surgery. Breast. 2011;20(Suppl 3):S92-5.

29. Veronesi U, Zurrida S. Breast conservation: current results and future perspectives at the European Institute of Oncology. Int J Cancer. 2007;120(7):1381-6.

30. Haloua MH, Krekel NM, Winters HA, Rietveld DH, Meijer S, Bloemers FW, et al. A systematic review of oncoplastic breastconserving surgery: current weaknesses and future prospects. Ann Surg. 2013;257(4):609-20.

31. Losken A, Ghazi B. An update on oncoplastic surgery. Plast Reconstr Surg. 2012;129(2):382e-3e.

32. Cardoso MJ, Cardoso JS, Vrieling C, Macmillan D, Rainsbury D, Heil $\mathrm{J}$, et al. Recommendations for the aesthetic evaluation of breast cancer conservative treatment. Breast Cancer Res Treat. 2012;135(3):629-37.

33. Christie D, O'Brien M, Christie J, Kron T, Ferguson S, Hamilton $\mathrm{C}$, et al. A comparison of methods of cosmetic assessment in breast conservation treatment. Breast. 1996;5:358-67.

34. Clarke D, Martinez A, Cox RS. Analysis of cosmetic results and complications in patients with stage I and II breast cancer treated by biopsy and irradiation. Int J Radiat Oncol Biol Phys. 1983;9(12):1807-13.

35. Cardoso MJ, Cardoso JS, Wild T, Krois W, Fitzal F. Comparing two objective methods for the aesthetic evaluation of breast cancer conservative treatment. Breast Cancer Res Treat. 2009;116(1):149-52.

36. Vrieling C, Collette L, Bartelink E, Borger JH, Brenninkmeyer SJ, Horiot JC, et al. Validation of the methods of cosmetic assessment after breast-conserving therapy in the EORTC "boost versus no boost" trial. EORTC Radiotherapy and Breast Cancer Cooperative Groups. European Organization for Research and Treatment of Cancer. Int J Radiat Oncol Biol Phys. 1999;45(3):667-76. 